\title{
To Explore the Experiences of Mothers Losing Biological Sons to Death through Alcoholism in Njatha-ini Village - Sagana - Kirinyaga County
}

\author{
Article by Editter N. Mugo \\ Ph.D Psychology, Texila American University \\ Email:njemu2002@gmail.com
}

\begin{abstract}
American Psychological Association defines alcoholism as:-

"an illness characterized by preoccupation with alcohol and loss of control over its consumption such as to lead to usually to intoxication if drinking is begun; by chronic to intoxication if drinking is begun; by chronicity, progression; and by tendency towards relapse" (Hoffman, 1975).

The aim of the study was to explore the experiences of mothers losing biological sons to death through alcoholism in njatha-ini village sagana - kirinyaga west county, Kenya. The target population was mothers with adult sons that have died through alcoholism. in Njatha-ini village Sagana areaKirinyaga County. The study design was qualitative and non-probability design was used utilizing snow-balling sampling. According to Orodho and Kombo (2002) sampling is the procedure a researcher uses to gather people, places and things to study. It is a set of respondents from a larger population for the purpose of a study. Seven mothers from the Ndia ethnic community located in Njatha-Ini Village, Kirinyaga West County in Kenya, were interviewed through the Focus group discussion. A chunk of written notes audio taped were then transcribed, read and re-read then grouped items together. The information was placed into emerging themes; responses coded and conceptualized, attributed and searched for meanings from the data segmentation.

The mothers bio-data was based on four key descriptions, the age of the mothers, age of sons at time of dying, duration since the death of the son and the circumstances under which the son died through alcoholism. The mothers aged between 52 and 78 years old, the dying sons aged between 17 and 38 years, the sons were dead between 8 months and 10 years and although death causative was alcoholism, the circumstances of dying for the seven sons ranged from one poisoned while drunk, two sons from alcohol induced accidents, one suicide, two overdosed, and one murdered whilst drunk.
\end{abstract}

Keywords: Mother, Son, Death, alcoholism

\section{Introduction to background information}

Njatha-ini Village - Sagana - Kirinyaga County, is one of the forty seven counties in Kenya. Kirinyaga County is Located in Central Kenya, it borders Meru to the North, Embu to the North East, East and South, Murang'a to the South West, and Nyeri to the West. The County has four wards, i.e., Mwea Ward, Gichugu Ward, Ndia Ward (which is the host of the study) and Kirinyaga Central Ward Sagana, which is central to this study, is one of the county's local Authorities. According to the County's Strategic Plan (2005-2010), Kirinyaga County is one of the poorest counties in Central region and it accounts for $1.5 \%$ of the national poverty. The main problems concerning population and development in the county include high rate and early marriages, HIV pandemic, increased numbers of single parenthood, increased orphans as well as consumption of illicit brews among the youth which translates to lack of employment, high mortality/morbidity and declining family incomes.

\section{Problem statement}

The cry of generations of mothers losing sons to Alcoholism is getting louder day after day across the world and the number of mothers falling in this experience keeps swelling day by day. Evidently there is little thought on these experiences of mothers especially in the rural areas where counselling 
Texila International Journal of Psychology

Volume 1, Issue 2, Dec 2016

support is negligible and little has been done on mothers to analyse the impact of losing sons to death specifically through alcoholism.

This is dissimilar to other scourges such as HIV/AIDS, Tuberculosis and malaria whose vulnerable communities have been documented and supported to cope. The experiences call for sober rethinking taking into consideration the many challenging effects the experiences subject mothers to which can compromise their health, even though this is not the only depressing experience that mothers go through. The situation increases mothers' vulnerability not considering other factors such as maternal mortality. In Kenya, part of the Vision 2030 is Health which is an element of the Social Pillar, and good health is expected to play an important role in boosting economic growth and poverty reduction. Mothers therefore have a role to play in the realization of Vision 2030. It is of utmost importance that we assist the bereaved family to avoid irreparable trauma and endless suffering. Too many people not given enough help either go through years of unresolved grief or require psychiatric help later (Kubler-Ross, 1974).

\section{Justification}

Most of alcoholism fatal cases, the casualty is the male gender and majority are young, compared to female. Mothers ruminate a lot about the death of a significant other more than other family members. Even prior to death, more often than not, it is the mother who worries about the alcoholism trend and will accompany the child to seek professional help, if at all, hence avid motivation to recollect the mothers' experiences over own sons' death.

\section{Broad objective}

To explore the experiences of mothers losing biological sons to death through alcoholism in Njatha-ini Village - Sagana - Kirinyaga County

\section{Knowledge}

Losing a child to death through alcoholism has emerged as one of the crushing and potentially destructive pains in mothers' lives. However, researches focusing on mothers that have lost sons to death through alcoholism are scarce. This study was quite limiting in that there are no past studies specifically to mothers' experiences of losing sons to death through alcoholism done in this locality.

\section{Methodology}

The study was done in Njatha-ii-village in Kirinyaga County and the target population were mothers that have lost sons through alcoholism. One of the key features of qualitative research is to give a voice to participants, focusing on enabling participants 'voices to be heard' by providing deep descriptions of phenomena being investigated (McLeod, 2001). The study explored human phenomenon perspective and considered the qualitative method, otherwise referred to by Kumar (1996) as naturalistic or subjective. The main objective of qualitative study is to describe the variations in a phenomenon, situation or attitude whereas the quantitative research in addition helps you to quantify that variation (Kumar, 1996). The study is rooted in the phenomenological paradigm being one of the traditions underpinning the qualitative research whereby it is concerned with questions about the nature of the object itself, but with the human subjective experience of perceiving and relating to the object. This is qualified by the fact that mothers' experiences touch on their feelings, thoughts and emotions and the study seeks to understand the mothers subjective experiences of having their sons die through alcoholism. Further qualitative research is rich in uncovering peoples' experiences looking at why situations are the way they are. Coolican (1990) argues strongly that some qualitative proponents the qualitative research method do not necessarily invoke greater subjectivity at all. The experiences can be written objectively and can be checked with them for accuracy and true reflection of earlier lived experiences, thus qualitative studies are almost always naturalistic and are conducted in more natural every day circumstances. 
According to Orodho and Kombo (2002) sampling is the procedure a researcher uses to gather people, places and things to study. It is a set of respondents from a larger population for the purpose of a study. A sample size of seven respondents as sample size requires minimal time and resource investment and this was small enough to give everyone the opportunity to express their opinion. The 7 were picked using snow-balling sampling out of 20 mothers that were willing. The following criterion was to work with the respondents:-

- Willingness for inclusion in the Focus Group discussion and answering corresponding questions

- Willingness to allow the interview be tape recorded

- Consent if the research is considered for the publication of the study.

- Mothers that have experienced the phenomenon of losing their biological sons to death through alcoholism.

- Adult mothers

- Volunteering

\section{Results}

Focus group participants bio-data information 
Texila International Journal of Psychology

Volume 1, Issue 2, Dec 2016

\begin{tabular}{|l|c|c|c|c|c|c|c|}
\hline Description & 1 & 2 & 3 & 4 & 5 & 6 & 7 \\
\hline Age of mother & 58 & 70 & 70 & 52 & 58 & 64 & 78 \\
\hline $\begin{array}{l}\text { Age of son at the } \\
\text { time of death }\end{array}$ & 38 & 30 & 25 & 25 & 17 & 27 & 23 \\
\hline $\begin{array}{l}\text { Duration since } \\
\text { death }\end{array}$ & 04 years & 03 years & $\begin{array}{c}10 \\
\text { years }\end{array}$ & 08 months & 18 years & 05 years & 10 years \\
\hline $\begin{array}{l}\text { Death } \\
\text { Circumstances }\end{array}$ & $\begin{array}{c}\text { Poisoned } \\
\text { while drunk }\end{array}$ & $\begin{array}{c}\text { Accident } \\
\text { occasioned by } \\
\text { alcoholism }\end{array}$ & Suicide & Overdosed & Overdosed & $\begin{array}{c}\text { Murdered } \\
\text { drunk }\end{array}$ & $\begin{array}{c}\text { Accident } \\
\text { while drunk }\end{array}$ \\
\hline
\end{tabular}


Some notable characteristics of the respondents that emerged that out of the seven respondents who had lost sons to death through alcoholism , only one respondent was not a widow The respondent's ages ranged between ages 58 and 78 years. The sons of the respondents had died between 8 months and 18 years ago. The deaths through alcoholism had happened through means of alcohol intoxication, poisoning, road accidents, suicide and murder. At the time the sons died, they were aged between 17 and 38 years. Twelve main themes emerged from the data analysis

\section{- Positive recollections on the dead sons}

The mothers of the dead sons had positive memories. It was clear that no matter what circumstances death occurred, there were fond memories and good deeds cherished over the years:

\section{- Feelings that come with loss}

Several forms of feelings were expressed in the experience that ranged from fear, bad pain, sadness; unhappiness, disturbed, being looked down upon, shame, depression, loneliness guilt, betrayal of parenting by the dead, emotional pain and insomnia associated with the loss is evident for the mothers in general.

\section{- Helplessness}

Helplessness was expressed especially in the effort of trying to heed the addicted stop drinking but the concerned would not stop even with the doctor's intervention and the medical warnings but again and due to compulsives of the alcoholism disease, the affected son was unable to stop and finally death strikes.

\section{- Traumatic \& untimely death}

Untimely death has been depicted as sudden, at any age, murders or even suicide, the unpredictability of accidents, and the death of young people has been proven as profoundly distressing.

\section{- Birth Order}

The birth position of the child within the family as well as the atmosphere of the family has been shown as playing a significant role in the family constellation and a major influence as to how a mother views death of same. First and last born have featured comparatively.

\section{- Stigma from the surrounding community}

The community has been shown as one of the put downs and reproach for the mothers in their experiences.

\section{- Grandmother's parenting inevitably}

With the son's dead and having left children and wives the mothers bury the sons and embark on active care of their grandchildren within their homes. They have spent all their strength and effort in bring up the children, educating them and giving them a sense of belonging. The process has been shown as draining as they handle their grandchildren and on the other hand they are mourning.

\section{- Cognizance of the effects of alcohol to families}

The effects of alcoholism are indeed in the awareness of the mothers and some worry if the other sons in the family just turn out to be like the deceased.

\section{- Coping with the loss}

Every other manner of coping was seen. Some respondents turned to their Higher Power, getting saved, others went to their fellow women and together they formed a fellowship, uniting with the church, others replaced the death memories with work, just working with their hands to make the 
mind feel calm, placing a telephone call to woman friend, prayer requests and women groups. These sustained the mothers in the absence of any formal settings in dealing with the loss of sons to death through alcoholism.

\section{- The act of letting go}

Some respondents moved to acceptance

Ones grief depends on one's personality, back-ground, religious believes, relationship with the deceased, and cultural environment. Even though the mourner may never recover completely, from the loss, most people return to a state of productivity and this process of normal grief is what Collins (1994) refers to as 'uncomplicated mourning'.

\section{- Suicidal ideation \& death}

Feeling grief, which naturally takes a surprising amount of physical energy, coupled with exhaustion my increase thoughts of suicide. These powerful suicidal thoughts are potentially very destructive and should be given the proper attention and care immediately.

The idea of the mothers coming together after experiencing the death of their husbands had naturally staffed the suicidal thoughts hanging themselves, they would die, they would get sick and get a heart failure,

Collins (1994) acknowledges that for some, there could be hyperactivity, giving up attitude of helplessness and hopelessness, intense guilt, a strong self-condemnation, extreme social withdrawal

\section{- 12. Self-concept}

Some mothers experienced poor relationships with the late sons' children and the left behind daughter in law. It is normal for human beings to experience poor inter-personal relationships especially when they are managing stress, undergoing a crisis or dealing with negative feelings.

\section{Discussion}

\section{Sudden trauma \& post traumatic stress}

When death or loss of any kind is sudden, it is hard and brings an overall sense that life is unfair and to put the immediate horror to rest is not easy. Such sudden traumatic deaths my come in form of murder, alcoholism overdose, accidents or even suicide which feels like a true nightmare. This is because life has given you no time to get used to the idea of having to say good bye. Feelings were expressed by the mothers as a result of the sudden death of their sons in terms of fear, bad pain, sadness; unhappiness, disturbed, depression, loneliness, guilt, betrayal, emotional pain and insomnia which is associated with the loss. There was anger, pain, rage, disbelief and regret which further complicate the grief. The pain for the survivors is complicated because the experience is sudden, typically unexpected and this may mean sometimes many years of working through the grief. Going by the experiences, some of the mothers are still struggling with disquiet which can be described as post-traumatic stress disorder or PTSD which is an anxiety disorder resultant from a traumatic experience such as losing a loved one. Indeed, Macin (2009) suggests that deaths that people think should not have happened produce highly visible grief.

\section{Community response}

African cultural tradition prescribes that when a child dies, the family and community rally around the mother for a few weeks, sitting with her, bringing food, cleaning her house, in addition to talking about the pain of the loss. And supposedly by the time of the funeral, family members have talked enough about the death and are ready to let go of the deceased child". This helped mothers to move on after death. Times have changed and from the study and own experience confirms that communities are no longer tightly knit and community members often do not know one another. Each family therefore struggles with their own grief unless very close family members are willing to share the 
burden and even for them, they soon retreat back to their own lives without ever returning to the grieving family.

No man is an island' It is not good and healthy to exist in isolation when death strikes and irrespective the causative factors, we need each other. Despite the western culture where people tend to value independence and individualism, locally we talk about co-operation and mutual support. But we rarely remember this and sometimes the assumption that personal problems are best handled alone, reigns. Ideally, the community should be giving acceptance, support and fellowship but more often than not, the mothers were faced with contempt and neither psychological support nor professional help was forthcoming for mothers who had lost sons to death through alcoholism. In America, groups such as Gay Bereavement Project, Jewish Bereavement Counselling Services are there to provide freely individual support and making public statement about overlooked losses. In this study it was revealed that it has fallen to individual grieving to draw attention to their own particular loss and grief experience. Many bereaved also point out that the behaviours of the people around them also change. People don't know what to say. They want to help in times of grief but do not know how. They may try to over-control in an attempt to be helpful.

\section{Changes}

Faith can be the source of great comfort at a time of loss. Most respondents affirmed their knowledge that their Higher Power is in control and took care of them during these difficult periods. They found praying, fellowshipping and working as a provider of special and needed comfort in their lives at this time. There were others whose changes happened behaviourally and could not sleep all the time. There are no rights or wrongs here and each respondent made a personal choice their pattern of change. Commenting on such changes, Peck (1994) underscored that often people who have had such experiences were not previously spiritual, but became so afterwards and invariably, they have come to believe in life after death and have a much diminished fear of death.

\section{Coping}

Whilst coming to terms with the fact that death of a loved one has occurred, more often than not this means getting help from others. Another way is to find support groups of people who have had similar experiences. In here, one can find the reassurance that they are not alone anymore and that you are not the only one who has undergone this kind of loss. It however remains the task of the bereaved to find out whom to include in their own circle of support from family and friends, congregation and community as well as support groups.

\section{Resilience}

There was evidence of repressive coping, but it is unclear to what extent this was natural emotional response and to what extent it was the only way these mothers could cope in light of the absence of support and the need to address more urgent daily needs of survival.

Support groups can offer important human contacts to those who are experiencing high levels of loneliness. Sensitivity is called for in counselling to the possible ways in which different cultures express themselves in their outer and inner worlds. However, realistically, the counsellor need not become an expert in different cultural orientations. Corey (2000) says that both self-help groups and therapy groups have a contribution to make in our society. Self - help groups are quite common with mothers especially even in circumstances that are not related to los of relatives through death. It improves on the resilience of mothers who seem quite strong even in the face of challenges of caring the young and the old.

\section{Conclusion and recommendation}

The study revealed that the experiences of mothers that have lost sons to death through alcoholism are the most universal of all losses and one of the crushing and potentially destructive pain in mothers. Their lonely life struggles to soldier on with their grief and their meagre Self Support Group to cope is 
Texila International Journal of Psychology

Volume 1, Issue 2, Dec 2016

untenable. That even though the loss of the sons may never get easier, it might be comforting to know that they are not alone on grieving their sons but may not feel so alone if they gather with other mothers who are equally mourning their lost children. Communities were unrealistic in shouldering their pain. Their healing path can be emulated and their learnt lessons can be supportive to mothers entering the loss for the first time

Appropriate support would equip the mothers in the future in the event the loss re-emerges. In the meantime, the needs of these mothers and the deceased's significant others (wife and children where applicable) deserve top priority and medical treatment needs to be combined with appropriate psychosocial support. Their experiences call for a National intervention.

Further and in conclusion, it was realized that although the mothers' hearts are broken and they cannot become so absorbed in their own loss that they fail to continue to be a light of those who have no hope. This may not be helpful just for the mothers that have lost sons just to alcoholism, but grief in general. From the discussion, it came out that to a larger extent most of the mothers struggled to move forward on their own in working on their emotions.

\section{Recommendations}

- This piece of study should in future be used as pilot study while developing future researches on the area.

- Such mothers should be supported by the government Agencies such as National Authority for Campaign Against Drugs (NACAADA) in Prevention.

- The County Government should endeavour to partner with Addiction Professionals to form Al-Anon and Alcoholic Anonymous Support Groups.

- The Kirinyaga County Administration should assist the group with meeting venue once a week.

- The emotional and physical burden on these bereaved mothers warrants further investigation, especially in light of associated health issues such as depression and post-Traumatic Stress.

- Replication of the study in future involving bigger samples and diverse groups, such as researches into the plight of losing a young husband and father of your children to alcoholism.

- It would be useful for future studies to measure the extent of resilience among these mothers and, more importantly, to examine which factors promote resilience. Community counselling to help build social support by promoting increased co-operation, communication to counter isolation amongst community members.

- Sensitization and awareness creation on bereavement to such mothers.

- National Augmenting of trained Counsellors and Psychologists

- Formulation of National Suicide Prevention Strategy by the Government.

- Cultural bereavement methods need to be revived in the community in order to help those who have buried their sons.

- This study is further recommended as a learning point to General Public, Government Agencies, individuals, Addiction and General Counsellors, bereaved communities; spiritual and lay leaders, prisons and Workplace can grasp the world of mothers that have lost sons to death through alcoholism as they bump into them in their midst. It is a lonely and a road without much understanding.

Acknowledgment

I seek to appreciate the 7 mothers that volunteered for the study and the Sagana Local Catholic Church which was an entry point for the study and its congregation. To all of you blessings.

\section{References}

[1] American Psychological Association (1987). Case Book in Ethical Principles of Psychologists. Washington: American Psychological Association. 
[2] Collins, N., \& Read, S. J. (1994). Cognitive representations of attachment: The structure and function of working models. In D. Perlman \& K. Bartholomew (Eds.), Advances in personal relationships (Vol. 5, pp. 5390). London: Jessica Kingsley

[3] Coolican, H. (1990). Research Methods and Statistics in Psychology. London: British Library Cataloguing in Publication Data.

[4] Corey, G. (2000). Theory \& Practice of Group Counselling. Wards worth: Brooks/Cole.

[5] Machin, L.(2009). Working With Loss and Grief. London: Sage Publications.

[6] McLeod J. (2001). Qualitative Research in Counselling \& Psychotherapy. London: Sage

[7] Orodho, A.J. \& Kombo, D.K. (2002). Research Methods. Kenyatta University: Institute of Open Learning.

[8] Peck, M. S. (1994). The Road less Travelled. New York: Library of Congress Cataloguing-in-Publication Data 